\title{
MANET Parameter Analysis and its Impact on Next Generation Network
}

\author{
Shadab Pasha Khan, M. A. Rizvi and Sitendra Tamrakar \\ Department of Computer Science \& Engineering \\ Chameli Devi Group of Institutions \\ Indore, India, \\ Department of Computer Engineering \& Applications \\ National Institute of Technical Teacher's Training \& Research \\ Bhopal, India, \\ Department of Computer Science \& Engineering \\ AISECT University \\ Bhopal,India \\ shadabpasha@gmail.com,marizvi@nitttrbpl.ac.in,drsitendra@gmail.com
}

\begin{abstract}
A mobile ad-hoc network is a type of network in which all the nodes can communicate each other without any fixed infrastructure. This unique property of MANET is useful in conditions where exchange of information is the prime objective under any circumstances. In this type of network all communicating nodes cooperate with each other in the distributed manner and offer dual responsibility, one as a host and the other as router. This quality of MANET paves the way for numerous new and exciting applications over Next Generation MANET. These applications may include, such as group communication, data telemetry, automotive applications, music and video streaming, real time mobile applications. Two main evolutions of multihop next generation ad hoc networks are projected, namely WMN and Opportunistic Networks. In this paper an honest attempt is made to enumerate and briefly discuss issues and challenges of Next Generation Network, parameters analysis and its impact.
\end{abstract}

Keywords: MANET, WMN, Ad-hoc

\section{Introduction}

The demand for high availability of network, high performance network, and high capacity network with more security is rapidly increasing to meet the pressing requirement of next generation user centric value added services like real time rich multimedia applications, interactive, distributed and collaborative applications, augmented reality applications and many more. These diverse applications aggravate the demand for high data rate services.

Compared to the last two decades Internet has an enormous growth and the same is expected in the Next Generation Network by connecting more entities (IoT) [1] to the network and enabling more applications and services. Mobile wireless communication has now become a necessity due to its versatility and utility convenience. A drastic change in our information society is achieved and we are moving towards ubiquitous age, where one can access information at any time and any place. But high speed networks are still essential. So we require the Next Generation Network to improve the throughput, speed and other factors. The wireless devices currently used fixed infrastructure based services to provide connectivity to the end user but this type of service requires lots of time and cost to establish the necessary infrastructure. 
In the case of emergencies all infrastructure based networks collapse but there is one network that exists against all odds i.e. Mobile Ad-hoc Network. MANET is a selfcreating, self-organizing and self-administering network. This network is an infrastructure less network, in which every node acts as a host as well as router for communicating with other nodes. MANET is gaining momentum because they offer network services with no pre-existing infrastructure or wireless links requirements [2]. Ad hoc nodes also connect to dedicated gateway to offer internet services to end user where pre-installed infrastructure is not available. Integration of MANET with other networks would also one of the most important features of Next Generation Network. All these options make Mobile Ad-hoc networking as an attractive option in future. Next Generation Network revolutionize the way we communicate by supporting rich multimedia applications that demand extremely high-speed wireless connections [3], lower latency and high throughput. To realize these benefits, Next Generation Network will differ fundamentally from their predecessors. MANET would be one of the integral parts of Next Generation Networks due to its unique characteristics.

This paper deals with MANET Characteristics, MANET Applications, MANET parameters, Next Generation Network and its Challenges, Targeted applications of Next Generation Modular Structure, System architecture and We therefore assess and presents the current state of different performance parameters associated with Next Generation MANET and certain open issues.

\section{MANET Characteristics}

\subsection{Wireless}

All the nodes are exchange the message without any physical medium. They send the messages through radio waves, infrared etc.

\subsection{Ad-hoc Based}

All the nodes are having capability to arrange themselves according to the situation as per the need arises and creates a network of dynamic in nature.

\subsection{Autonomous network}

This type of network does not need any centralized authority to look after the nodes during communication because node itself plays two roles: one as a host and another as a router.

\subsection{Multihop Routing}

During the entire communication each node is having dual responsibility; it acts like a router to control the operations performed as well as it works as mobile host also.

\subsection{Mobility}

Every node in this network is capable of moving from one place to another while communicating with other nodes and creates topology according to the need arises

\section{MANET Applications}

Due to the tremendous influence of mobile in day to day life, the commercial sector and standard communities realized the need of applications based on technologies such as Bluetooth, IEEE 802.11, Hyper lan and others that support mobile ad hoc networking to a large extent. Due to its unique features, MANET is very useful to real world applications 
where the entire network structure or topology changes dynamically [4]. As a result, many new ad hoc networking applications conceived which are as follows

\subsection{Tactical Networks}

This network plays very important role during war in battlefield for exchange of information in respect of situational awareness among tactical force units.

\subsection{Sensor Networks}

This network is mainly used in battlefield surveillance, monitoring and control activities to collect real time data of various industrial and consumer applications such as environmental monitoring, health monitoring and industrial process monitoring and so on.

\subsection{Emergency Services}

These services are often required in case of natural disasters like earthquakes, tsunami, and hurricanes; fire etc. when fixed infrastructure gets damaged.

\subsection{Commercial environments}

MANET is a key component of Intelligent Transportation System (ITS) as a VANET. Various Business activities and E-Commerce are also not left behind.

\subsection{Home and Enterprise Networking}

Personal Area Network (PAN) is a short distance communication network frequently used in information exchange in home and enterprise. PDA's and wireless networking are also used in ad-hoc manner.

\subsection{Educational Applications}

MANET is also used in establishing virtual classrooms or conference rooms in which distributed and collaborative sharing takes place.

\subsection{Entertainment}

MANET is also used in Multiuser games, robotic pets and outdoor Internet access.

\subsection{Location Aware Services}

These services deliver information regarding the physical location of any device to another user or application. It is one of the inbuilt features of present technology.

\section{MANET Parameters}

\subsection{Bandwidth}

The capacity of the channel which decides the maximum rate of information exchanged is known as Bandwidth. It is commonly measured in bits/second.

\subsection{Throughput}

The actual rate of successful transmission of bits / messages per unit time. It is affected by bandwidth of channel, signal to noise ratio and hardware devices. [5]

\subsection{Latency}


It indicates any kind of delay occurred in data communication network. It may be small delays or long delays. The networks having small delays are calls low latency networks. The network having long delays are called high latency networks. Bandwidth of the entire channel gets affected either temporary or persistent based of quantity and source of delays. The delay between the two ends i.e. from source to destination is called end to end delay (EED). [6]

Time taken by the message for the complete arrival at the destination is known as Latency or delay. It depends upon four components: propagation time, transmission time, queuing time and processing delay.

Latency =propagation time +transmission time +queuing time + processing delay

\subsection{Jitter}

It is one of the most important parameter which directly hampers the continuous transmission of packets across the network. It occurred due to network congestion, configuration errors. In other words, it is defined as the variation in the delay of packets received instead of remaining constant. [6]. It is also called Packet Delay Variation (PDV). It is end to end delay between selected packets in a flow. It is important QoS factor in network performance.

\subsection{Bit Error rate:}

The rate at which the error occurred is known as Error rate. Errors are observed due to interference, distortion. The number of corrupted bits expressed as a percentage or fraction of the total sent. Bit error rate (BER) is also known as bit error ratio. It is defined as follows

BER=Number of bit errors / Total number of transferred bits

\subsection{Packet Delivery Ratio (PDR):}

It is the ratio of actual packet delivered to total packets sent. [5] $\mathrm{PDR}=$ Actual packet delivered $/$ Total packet sent

\subsection{Route discovery time:}

The time needed for the source node to discover a route to the destination.

\subsection{Route reconstruction time:}

The time taken upon triggering route reconstruction or repair (when mobility occurs) till completion.

\section{Next Generation Network}

Next generation network is all about convergence of various technologies. As it is observed that the internet is now an integral part of human society. Providing services to end user to enhance the user experience about the network.

Next Generation Network is a Self-Network, Trustable Network, Sustainable Network, Ambient / Ubiquitous network and Value Creation Network. Next Generation Wireless Networks will provide better services Out of these above Self-Network, Ubiquitous network and Value Creation Network are key objectives of MANEt also. Therefore, Mobile ad-hoc network plays critical role in Next Generation Network. Two key technologies Wireless Mesh Network (WMN) and Opportunistic Network has evolved recently to meet the requirement for the next generation futuristic mobile applications. 


\section{Wireless Mesh Network}

A network in which all the connecting radio nodes are organized in a mesh topology. All the radio nodes often laptops, cell phones and other wireless devices communicates each other through various intermediate devices like routers and gateways where connectivity to the Internet is not needed.

\section{Opportunistic Network}

This network is one of the emerging networks that formed opportunistically based on proximity and availability of nodes (communication link) by randomly connecting and disconnecting the devices. The opportunistic networking paradigm is one of the most suitable paradigms for heterogeneous networking environment of next generation network where wireless hybrid architectures are used. Opportunistic network are tightly coupled with social network because they connect each other when humans come into contact. Therefore, the opportunistic network [7] supports wide variety of future mobile applications in pervasive environment of next generation network.

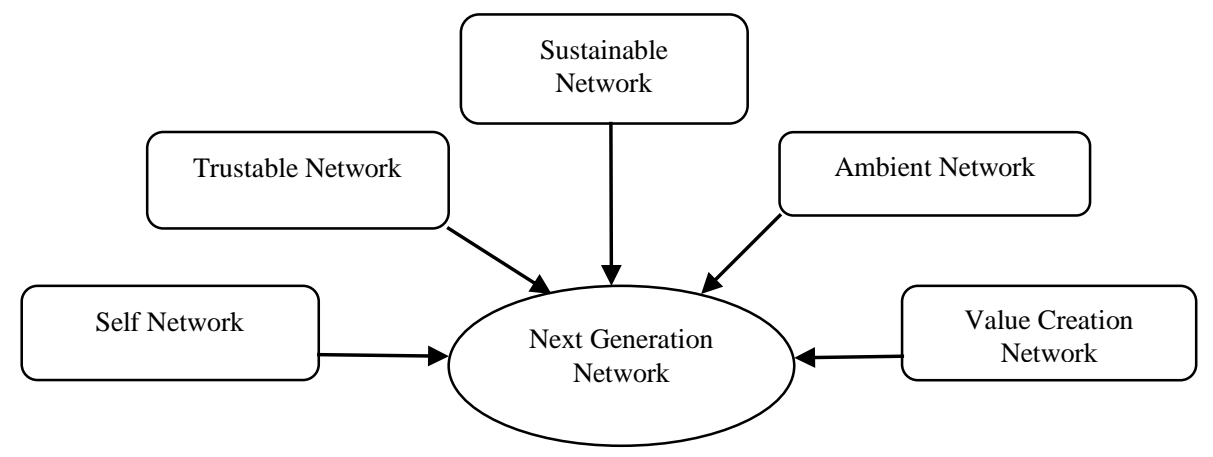

Figure 1. Next Generation Network Features

\subsection{Challenges of Next Generation MANET}

- $\quad$ Complexity of Telecom networks increased in multiple tiers

- $\quad$ Huge growth of volume of traffic

- $\quad$ Support for more number of users ( All IP network)

- $\quad$ Radio Access Network,IP transport, MS

- $\quad$ QoS must be guaranteed in all tiers.

- $\quad$ QoS signaling latency impacts

- $\quad$ Post Dial Delay- Time taken when you press a button of mobile phone, to acquire a service.

- Handoff Latency-During movement inside the network session interruption would be minimum.

- $\quad$ Multiple Design Alternatives-( To deploy Next Generation Network)

- $\quad$ Many policy management platforms

- $\quad$ Many architectural options (flat, hierarchical, hybrid)

\section{Future Consumer Targeted Applications}

There are various applications; few of them are listed below: [8]

- Only precise services will be provided on demand.

- Nice Value added services.

- Location based services. 
- Rich Multimedia Services IP Multimedia Services (IMS)

- Mobile TV

- VOIP

- Video Conferencing

- Instant Messaging / Group Communication

- Data Telemetry

- Automotive Application

- Music \& Video Streaming

- Real time mobile applications

\section{Next Generation Modular Structure}

Modular structure of Next Generation Network consists of access and transport layer, media layer, control layer and network service layer. The next generation network required gateways to connect entirely different kind of networks. Various intermediate devices are interconnected each other to route the traffic from one layer to another layer and finally to the end user.

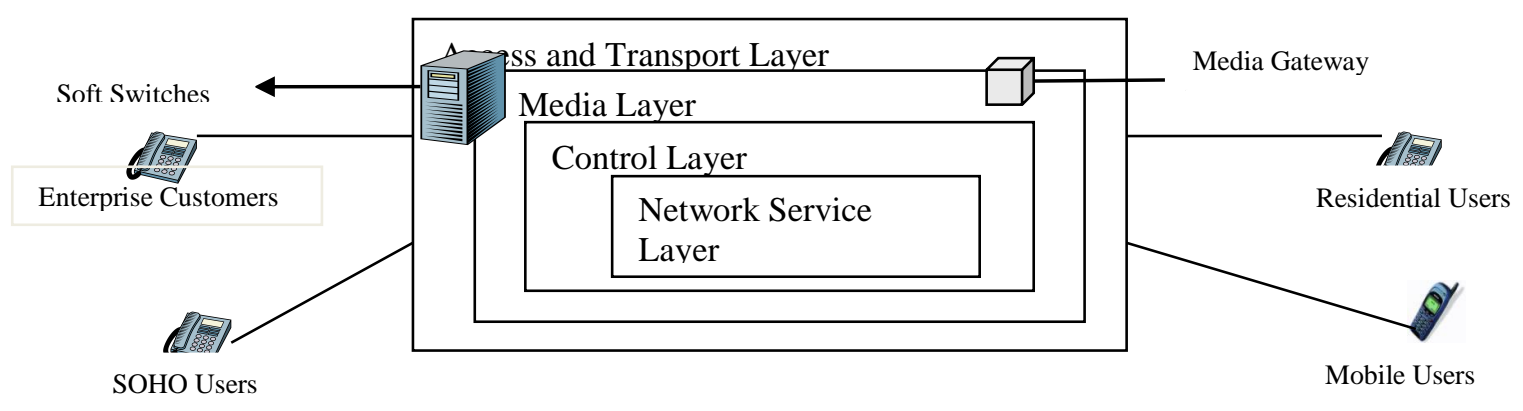

\section{Next Generation System Architecture}

Next Generation network would provide advanced services to support wide range of user centric applications. We need architecture that supports user centric customized on demand and real time applications. There are various wireless architectures available out of that the integrated cellular and ad hoc relaying system (iCAR) will provide us advanced services required to run on demand user centric real time advanced applications. The iCAR architecture [9]consist of number of ad hoc relaying systems (ARSs) which is placed in such a way so that it can transfer excess call traffic from heavily loaded cell to lightly loaded cell. These ad hoc relaying systems (ARSs) are wireless routing devices.

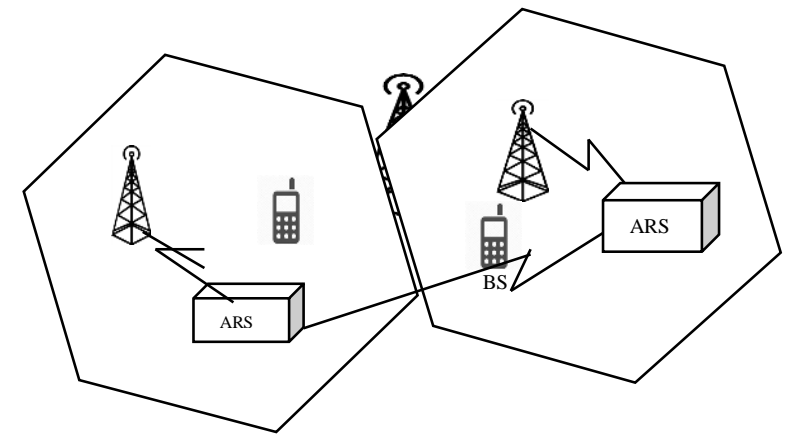

Figure 3. iCAR Architecture 


\section{Performance Parameters of MANET of various Generations}

Performance parameters of various generations from $1 \mathrm{G}$ to $5 \mathrm{G}$ are being done on specified parameters. [10, 11]. It depicts how the value of different parameters varies.

Table 1. Performance Parameters of Next Generation Network

\begin{tabular}{|c|c|c|c|c|c|c|c|}
\hline $\begin{array}{c}\text { Paramete } \\
\text { rs }\end{array}$ & $1 G$ & $2 G$ & $2.5 \mathrm{G}$ & 3G & 4G & $5 G$ & $\begin{array}{c}\text { Next } \\
\text { Generati } \\
\text { on } \\
\text { Network }\end{array}$ \\
\hline Signal & Analog & Digital & Digital & Digital & Digital & Digital & Digital \\
\hline Structure & $\begin{array}{l}\text { Infrastru } \\
\text { cture } \\
\text { based }\end{array}$ & $\begin{array}{l}\text { Infrastruc } \\
\text { ture } \\
\text { based }\end{array}$ & $\begin{array}{l}\text { Infrastruc } \\
\text { ture } \\
\text { based }\end{array}$ & $\begin{array}{l}\text { Infrastruct } \\
\text { ur-e based }\end{array}$ & $\begin{array}{l}\text { Hybrid } \\
\text { of } \\
\text { Infrastru } \\
\text { ctu-re } \\
\text { based \& } \\
\text { ad-hoc } \\
\text { based }\end{array}$ & $\begin{array}{l}\text { Hybrid } \\
\text { of } \\
\text { Infrastru } \\
\text { cture } \\
\text { based } \\
\text { and ad- } \\
\text { hoc } \\
\text { based }\end{array}$ & $\begin{array}{l}\text { Hybrid of } \\
\text { Infrastruc } \\
\text { tur-e } \\
\text { based and } \\
\text { ad-hoc } \\
\text { based }\end{array}$ \\
\hline Speed & $\begin{array}{c}\text { Upto } 2.4 \\
\text { kbps }\end{array}$ & $\begin{array}{l}\text { Upto } \\
\text { 64kbps }\end{array}$ & $\begin{array}{c}64-144 \\
\text { kbps }\end{array}$ & $\begin{array}{c}144 \text { kbps- } \\
2 \text { Mbps }\end{array}$ & $\begin{array}{l}4 \text { Mbps - } \\
12 \text { Mbps }\end{array}$ & $\begin{array}{c}100 \\
\text { Mbps -1 } \\
\text { Gbps }\end{array}$ & --- \\
\hline Switching & $\begin{array}{c}\text { Circuit } \\
\text { Switche } \\
\text { d }\end{array}$ & $\begin{array}{c}\text { Circuit } \\
\text { Switched }\end{array}$ & $\begin{array}{c}\text { Circuit } \\
\text { Switched }\end{array}$ & $\begin{array}{c}\text { Circuit } \\
\text { Switched } \\
\text { and packet } \\
\text { switched }\end{array}$ & $\begin{array}{c}\text { Evolved } \\
\text { Packet } \\
\text { Core }\end{array}$ & $\begin{array}{c}\text { Evolved } \\
\text { Packet } \\
\text { Core }\end{array}$ & $\begin{array}{c}\text { Evolved } \\
\text { Packet } \\
\text { Core }\end{array}$ \\
\hline Access & $\begin{array}{l}\text { FDMA/ } \\
\text { FDD }\end{array}$ & $\begin{array}{c}\text { TDMA/F } \\
\text { DD,CDM } \\
\text { A/FDD }\end{array}$ & $\begin{array}{c}\text { EDGE/G } \\
\text { PRS }\end{array}$ & $\begin{array}{c}\text { CDMA,W } \\
- \\
\text { CDMA,T } \\
\text { D- } \\
\text { SCDMA }\end{array}$ & $\begin{array}{l}\text { MC- } \\
\text { CDMA, } \\
\text { OFDM }\end{array}$ & $\begin{array}{l}\text { MC- } \\
\text { CDMA, } \\
\text { OFDM }\end{array}$ & $\begin{array}{c}\text { OFDM \& } \\
\text { others }\end{array}$ \\
\hline IP Support & N/A & N/A & N/A & $\begin{array}{c}\text { Use } \\
\text { several air } \\
\text { link } \\
\text { protocols, } \\
\text { including } \\
\text { IP 5.0 }\end{array}$ & $\begin{array}{c}\text { All IP } \\
\text { based (IP } \\
\text { v 6) }\end{array}$ & $\begin{array}{c}\text { All IP } \\
\text { based (IP } \\
\text { v 6) }\end{array}$ & $\begin{array}{c}\text { All IP } \\
\text { based (IP } \\
\text { v 6) }\end{array}$ \\
\hline $\begin{array}{c}\text { Core } \\
\text { Network }\end{array}$ & PSTN & PSTN & -------- & $\begin{array}{l}\text { Packet } \\
\text { network }\end{array}$ & Internet & Internet & Internet \\
\hline Handoff & $\begin{array}{l}\text { Horizont } \\
\text { al }\end{array}$ & $\begin{array}{c}\text { Horizonta } \\
1\end{array}$ & $\begin{array}{c}\text { Horizonta } \\
1\end{array}$ & $\begin{array}{l}\text { Horizontal } \\
\& \text { Vertical }\end{array}$ & $\begin{array}{l}\text { Horizont } \\
\text { al \& } \\
\text { Vertical }\end{array}$ & $\begin{array}{l}\text { Horizont } \\
\text { al \& } \\
\text { Vertical }\end{array}$ & $\begin{array}{c}\text { Horizonta } \\
1 \& \\
\text { Vertical }\end{array}$ \\
\hline $\begin{array}{l}\text { Approxim } \\
\text { ate } \\
\text { Latency }(\mathrm{m} \\
\mathrm{s})\end{array}$ & $650-800$ & $500-650$ & $300-450$ & $100-300$ & 50 & $1-10$ & $\begin{array}{l}\text { Extremel } \\
\text { y reduced }\end{array}$ \\
\hline $\begin{array}{c}\text { Memory } \\
\text { (RAM) }\end{array}$ & $\begin{array}{l}\text { Very } \\
\text { Less }\end{array}$ & Less & Average & Good & High & $\begin{array}{c}\text { Increase } \\
\mathrm{d}\end{array}$ & High \\
\hline
\end{tabular}




\begin{tabular}{|c|c|c|c|c|c|c|c|}
\hline $\begin{array}{c}\text { Packet } \\
\text { loss } \\
\text { probabilit } \\
\text { y }\end{array}$ & High & High & $\begin{array}{c}\text { Less than } \\
\text { 2G }\end{array}$ & Reduced. & Reduced & $\begin{array}{c}\text { Extremel } \\
\text { y } \\
\text { reduced }\end{array}$ & $\begin{array}{c}\text { Extremel } \\
\text { y reduced }\end{array}$ \\
\hline $\begin{array}{c}\text { Paramete } \\
\text { rs }\end{array}$ & $\mathbf{1 G}$ & $\mathbf{2 G}$ & $\mathbf{2 . 5} \mathbf{G}$ & $\mathbf{3 G}$ & $\mathbf{4 G}$ & $\mathbf{5 G}$ & $\begin{array}{c}\text { Next } \\
\text { Generati } \\
\text { on } \\
\text { Network }\end{array}$ \\
\hline $\begin{array}{c}\text { Unlicense } \\
\text { d } \\
\text { spectrum } \\
\text { support }\end{array}$ & No & No & No & No & No & Yes & Yes \\
\hline $\begin{array}{c}\text { Self- } \\
\text { Organizin } \\
\text { g Network }\end{array}$ & No & No & No & No & No & Yes & Yes \\
\hline
\end{tabular}

From the above analysis of version of mobile network, it is evident that there is tremendous growth in the capabilities of the network and also in reliability and speed. Day by day the needs of society are changing and demands more feature and bandwidth according to the nature of the application is being launched. In the current situation next Generation Network is catching the attention in the society in both ways in terms of usage and among researchers.

\section{Conclusion}

This paper highlights the role of integrated cellular and ad hoc relaying system (iCAR) architecture in next generation MANET. The ad hoc relaying system (ARS) have gained more importance in the field of next generation MANET, which acts as an interface between the BS and ARS of adjacent cell to offer load balancing on real time. A brief overview of next generation modular structure is discussed. Future consumer targeted applications like rich multimedia applications; real time mobile applications etc. along with challenges of next generation MANET are listed.

Also explores the effect of different performance parameters of various generations and predict the features for next generation network like enhancement of user experience to a greater extent in terms of better services with minimum latency. This upcoming next generation network would be one of the derivatives of WMN and opportunistic network which will be trustworthy communication network. It provides high flexibility and scalability with low infrastructure cost. More number of devices would support that network.

\section{References}

[1] A. A. Fuqaha, M. Guizani, M. Mohammadi, M. Aledhari and M. Ayyash, "Internet of Things: A Survey on Enabling Technologies, Protocols, and Applications", IEEE Communication Surveys \& Tutorials, vol. 17, no. 4, (2015).

[2] Z. Li and H. Shen, "A QoS-Oriented Distributed Routing Protocol for Hybrid Wireless Networks", IEEE Transactions on Mobile Computing, vol. 13, no. 3, (2014).

[3] E. S. Altubaishi, "An Efficient Hybrid Scheduling Algorithm for High Speed Cellular Networks", IEEE, (2014).

[4] M. M. Alani, "MANET security: A survey", In International conference on Control, (2014).

[5] Z. D. Katheeth and K. K. Raman, "Performance Evaluation with Throughput and Packet Delivery Ratio for Mobile Ad-hoc Networks", vol. 3, iss. 5, (2014), IJARCCE,2014, ISSN (Online):2278-1021, ISSN (Print), pp. 2319-5940.

[6] S. Hakak, F. Anwar, S. A. Latif, G. Gilkar and M. K. Alam, "Impact of packet size and node mobility pause time on average end to end delay and Jitter on MANET's", ICCCE, IEEE, (2014). 
[7] M. K. Yogi and V. Chinthala, "A Study of Opportunistic Networks for Efficient Ubiquitous Computing", 2014, International Journal of Advanced Research in Computer and Communication Engineering, vol. 3, iss. 1January (2014).

[8] N. Radia, Y. Zhang and M. Tatipamula, "Next-Generation Applications on Cellular Networks: Trends, Challenges, and Solutions", IEEE 2012, vol. 100, no. 4, (2012).

[9] G. Jisha, P. Samuel and V. Paul, "Role of Gateways in MANET Integration Scenarios", Indian Journal of Science and Technology, vol. 9, no. 3, (2016).

[10] D. Stezenbach, M. Hartmann and K. Tutschku, "Parameters and Challenges for Virtual Network Embedding in the Future Internet", (2012).

[11] H. Viswanathan and M. Weldon, "The past.present and future of mobile communications", Bell Labs Technical Journal, vol. 19, (2014).
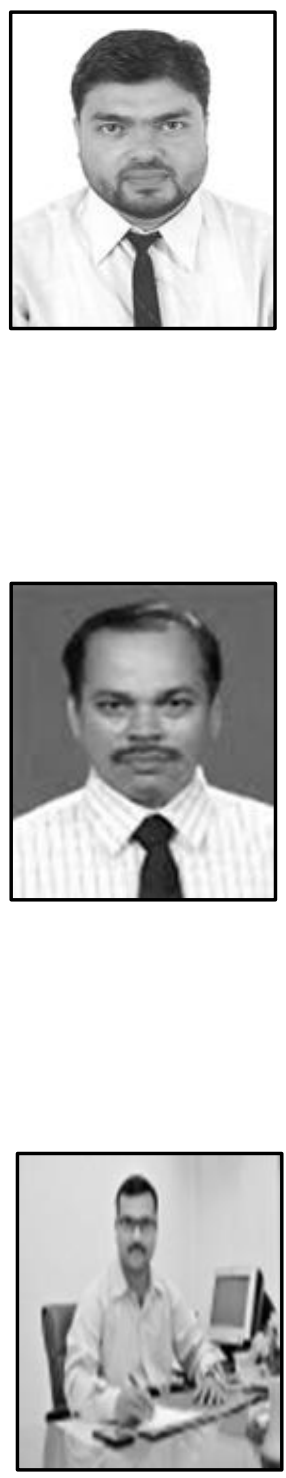

\section{Authors}

Shadab Pasha Khan, he has over a decade of teaching experience in various academic institutions of central India. Currently he is working as an Assistant Professor at CDGI, Indore. His research interest is in the area of Computer Network, Mobile ad-hoc network and Next Generation Network. He published and presented research papers in various National, International Conferences and Journals. He was appointed as Workshop Coordinator for Computer Networking Workshop conducted by IIT- Bombay. He attended many workshops conducted by IIT Bombay and IIT Kharagpur under National Mission on Education through ICT, MHRD, Govt. of India. He is a life member of ISTE and CRSI.

M. A. Rizvi, he has obtained his Doctorate in Computer Science from (MANIT) Bhopal. Dr. Rizvi Presented Research in an International Conference at University of California San Francisco, USA where he was rated second. He was honoured to chair one of the session of an International conference organized by World Congress on Education (WCE 2013) held in London. Dr. Rizvi has more than 25 years of experience in the field of Computer Science and Applications as faculty (Associate Professor) and Head of the Dept. in (NITTTR), Bhopal a Govt. of India Institute. He has published approximately 100 research papers in reputed International Journals and International Conferences across the globe.

Sitendra Tamrakar, he had completed his $\mathrm{PhD}$ in Computer Science and Engineering, he is research supervisor in AISECT University which is a renowned name for research. He has published numerous research papers in national and international journals and conferences. His research interests are MANET and image processing. 
International Journal of Future Generation Communication and Networking Vol. 9, No. 12 (2016) 